\title{
Curvature-Dependent Oxidation of Gold Nanoparticles by Au(III)-CTAB Complexes
}

Jessica Rodríguez-Fernández, Jorge Pérez-Juste, Paul Mulvaney, Luis M. Liz-Marzán

\section{Discussion on the effect of bromide ions on the equilibrium constant of equation (1):}

For the discussion of the redox reaction (1) between $\mathrm{AuCl}_{4}^{-}$and $\mathrm{Au}^{0}$ in the presence of CTAB, the possibility of having $\mathrm{AuBr}_{4}{ }^{-}$and $\mathrm{AuBr}_{2}{ }^{-}$instead of $\mathrm{AuCl}_{4}{ }^{-}$and $\mathrm{AuCl}_{2}{ }^{-}$should be considered, since at least two of the chloride ions can be exchanged by bromide. The redox potentials are then:

$$
\begin{array}{ll}
\mathrm{AuBr}_{2}{ }^{-}+\mathrm{e}^{-}=\mathrm{Au}^{0}+2 \mathrm{Br}^{-} & \mathrm{Eo}=+0.959 \mathrm{~V}(\mathrm{NHE}) \\
\mathrm{AuBr}_{4}{ }^{-}+2 \mathrm{e}^{-}=\mathrm{AuBr}_{2}^{-}+2 \mathrm{Br}^{-} & \mathrm{Eo}=+0.802 \mathrm{~V}(\mathrm{NHE}) \\
\mathrm{AuBr}_{4}{ }^{-}+3 \mathrm{e}^{-}=\mathrm{Au}+3 \mathrm{Br}^{-} & \mathrm{Eo}=+0.854 \mathrm{~V}(\mathrm{NHE})
\end{array}
$$

The value of the equilibrium constant for the conproportionation of $\mathrm{AuBr}_{2}{ }^{-}$can then be calculated as:

$$
\mathrm{AuBr}_{4}^{-}+2 \mathrm{Au}+2 \mathrm{Br}^{-}=3 \mathrm{AuBr}_{2}^{-} \quad \mathrm{K}=4.92 \times 10^{-6}
$$

being almost 260 times higher than in the case of gold chloride ions.

Additionally, the presence of CTAB $0.05 \mathrm{M}$ leads to another change in the equilibrium constant since now the free bromide ions arising from surfactant dissociation must be considered. Assuming a value of $§=0.8$ ( $ß$ being the fraction of micellar charge neutralized by the counterions), at least $20 \%$ of the bromide from CTAB will be in solution. Hence, if [CTAB] $=0.05 \mathrm{M}$, then $0.01 \mathrm{M} \mathrm{Br}^{-}$enters the equilibrium and,

$\mathrm{K}>\left(3.75 \times 10^{-4}\right)^{3} /\left[1 \times 10^{-6} \times(0.01)^{2}\right)=0.527$

The value of the constant is thus lower, but still the equilibrium constant will increase at least by a factor of $1.07 \times 10^{5}$ due to binding with CTAB. It should be taken into account that an amount of $\mathrm{AuBr}_{2}{ }^{-}$-CTAB left in solution of $1 \mu \mathrm{M}$ has been used, while it can be considerably lower. 
Supporting Information Figure 1. TEM micrographs and ellipticity distributions (histograms) of $\mathrm{Au}$ nanoparticles before (a) and after addition of $\mathrm{HAuCl}_{4}$ with different $\mathrm{Au}: \mathrm{Au}^{\mathrm{III}}$ molar ratios [1:0.125 (b), 1:0.25 (c), 1:0.30 (d), 1:0.34 (e), 1:0.4 (f)] in the presence of CTAB $0.05 \mathrm{M}$.

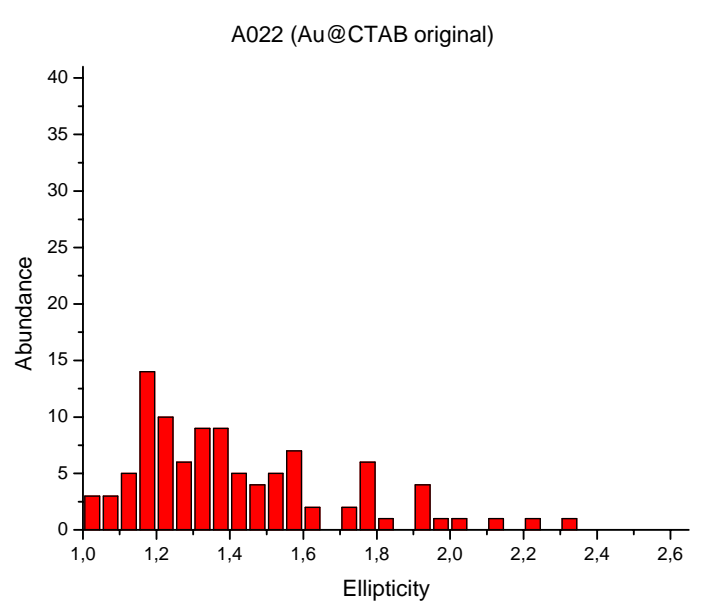

(a)
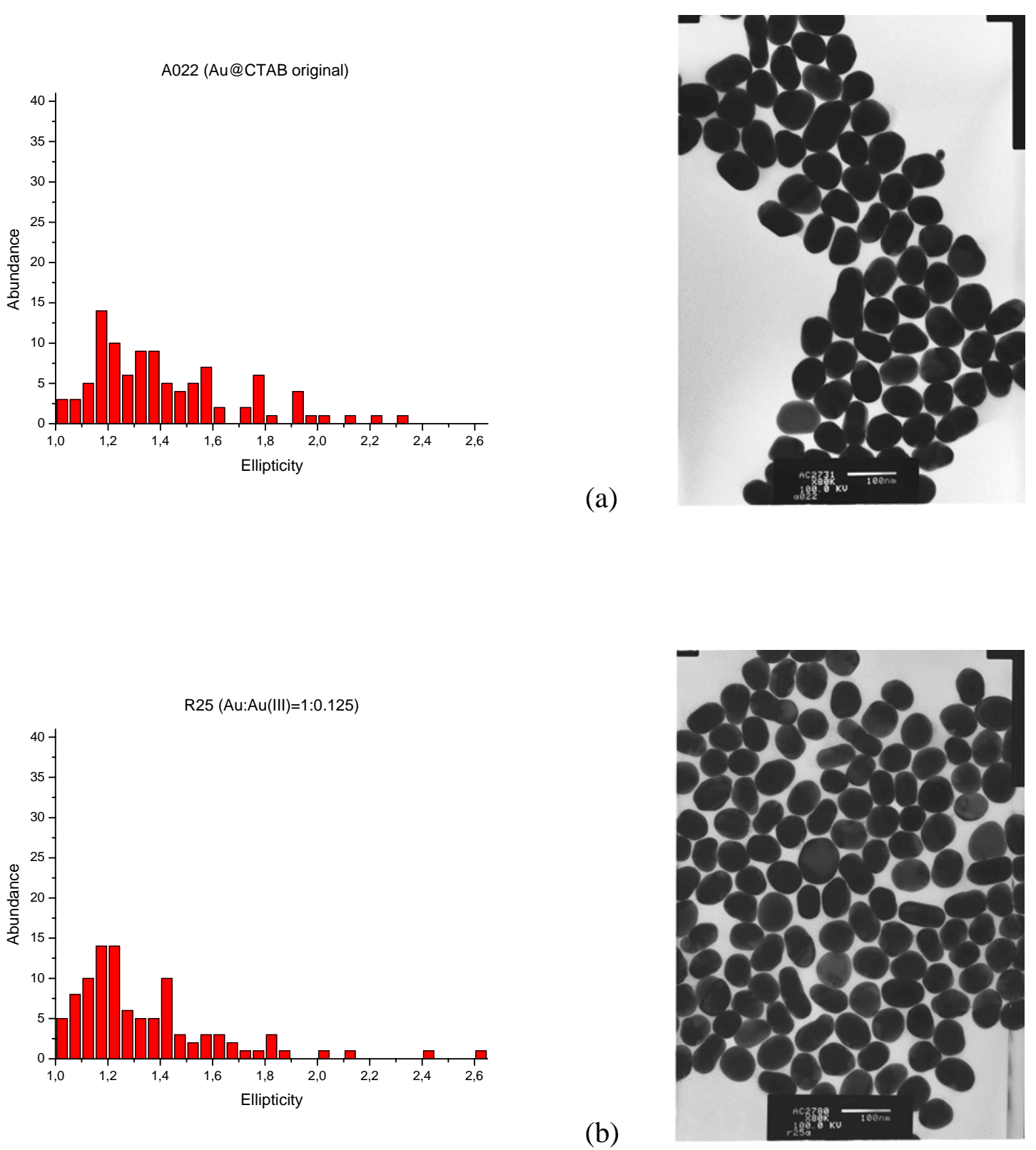

(b) 

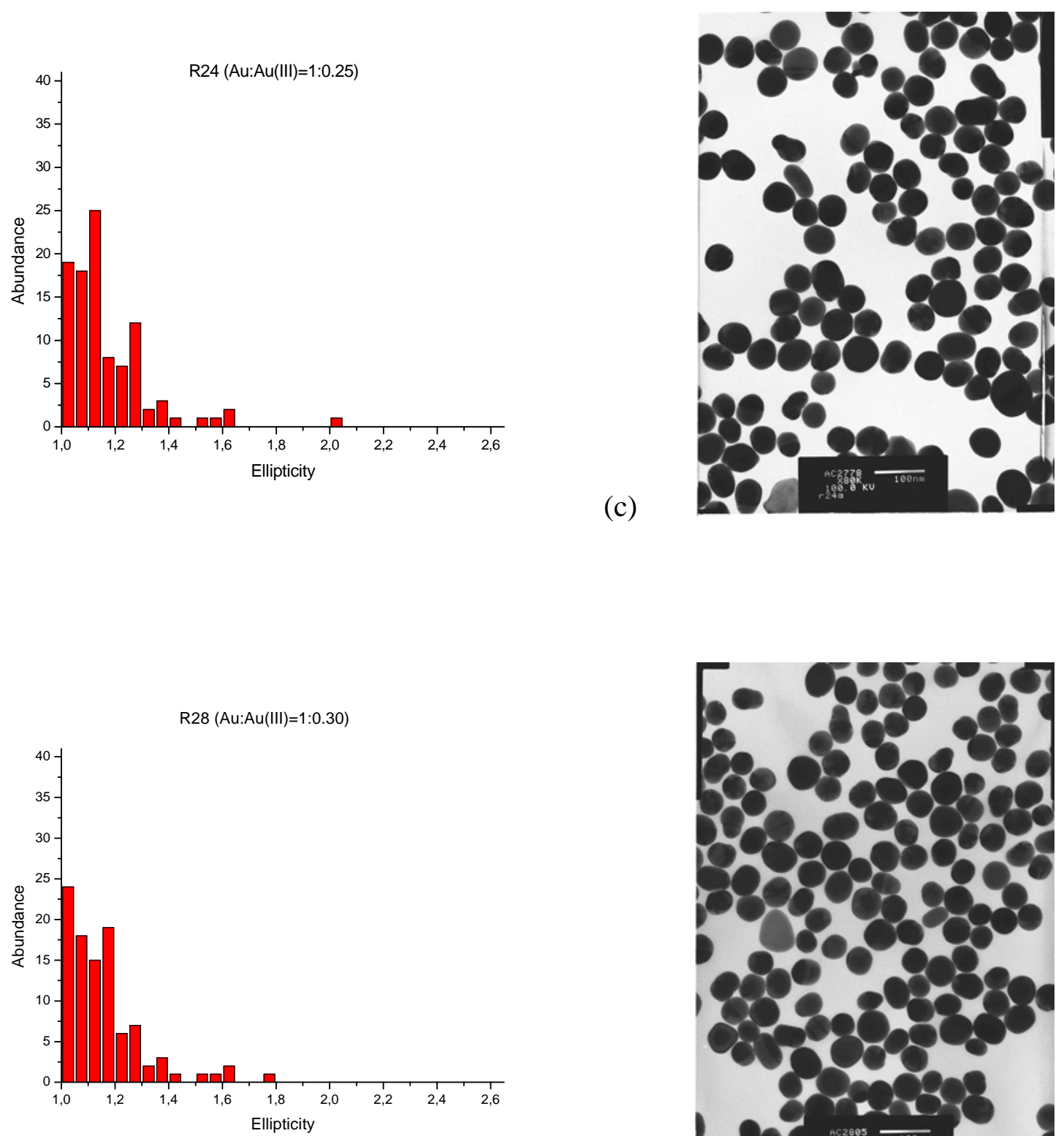

(d)
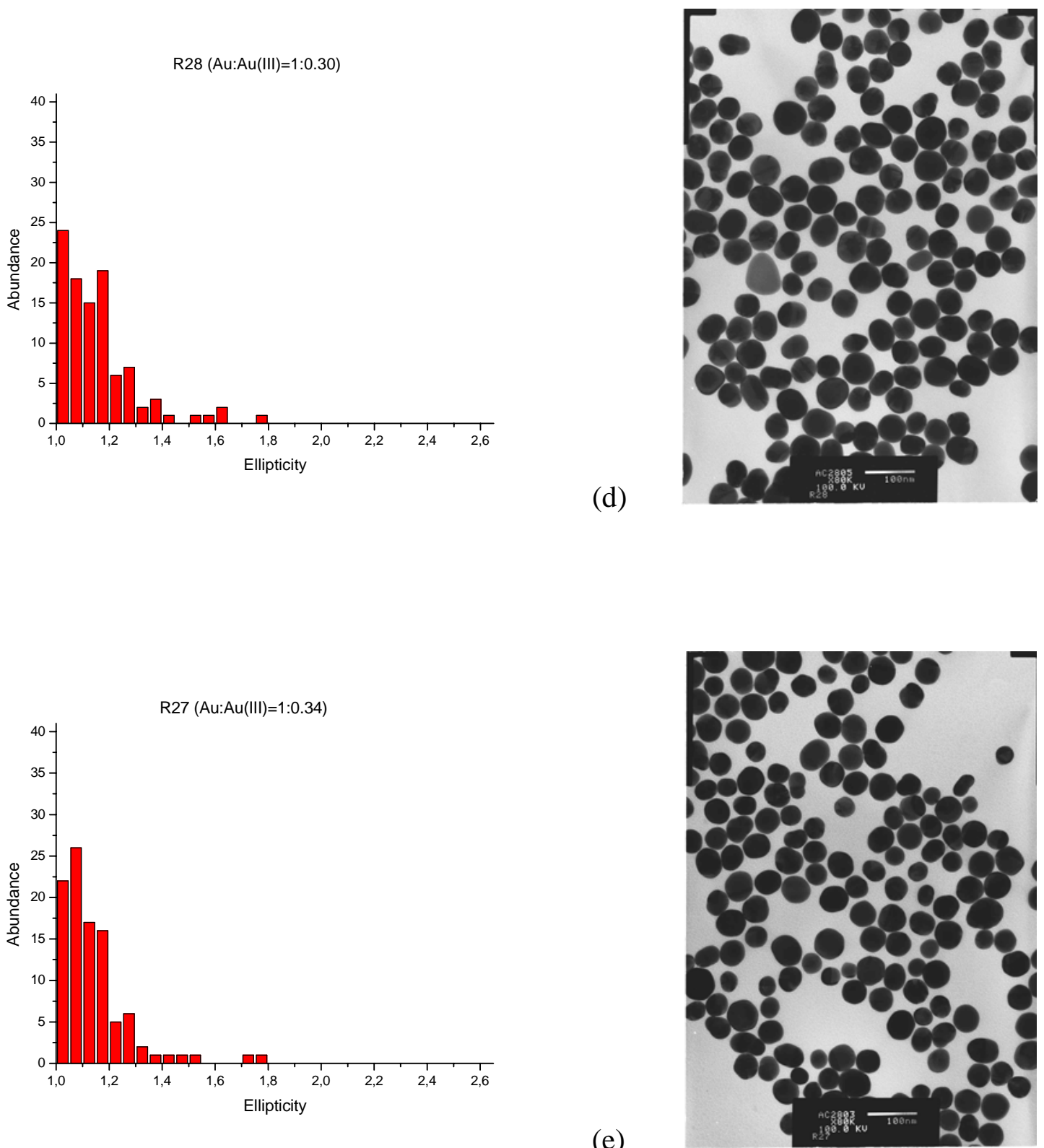

(e) 

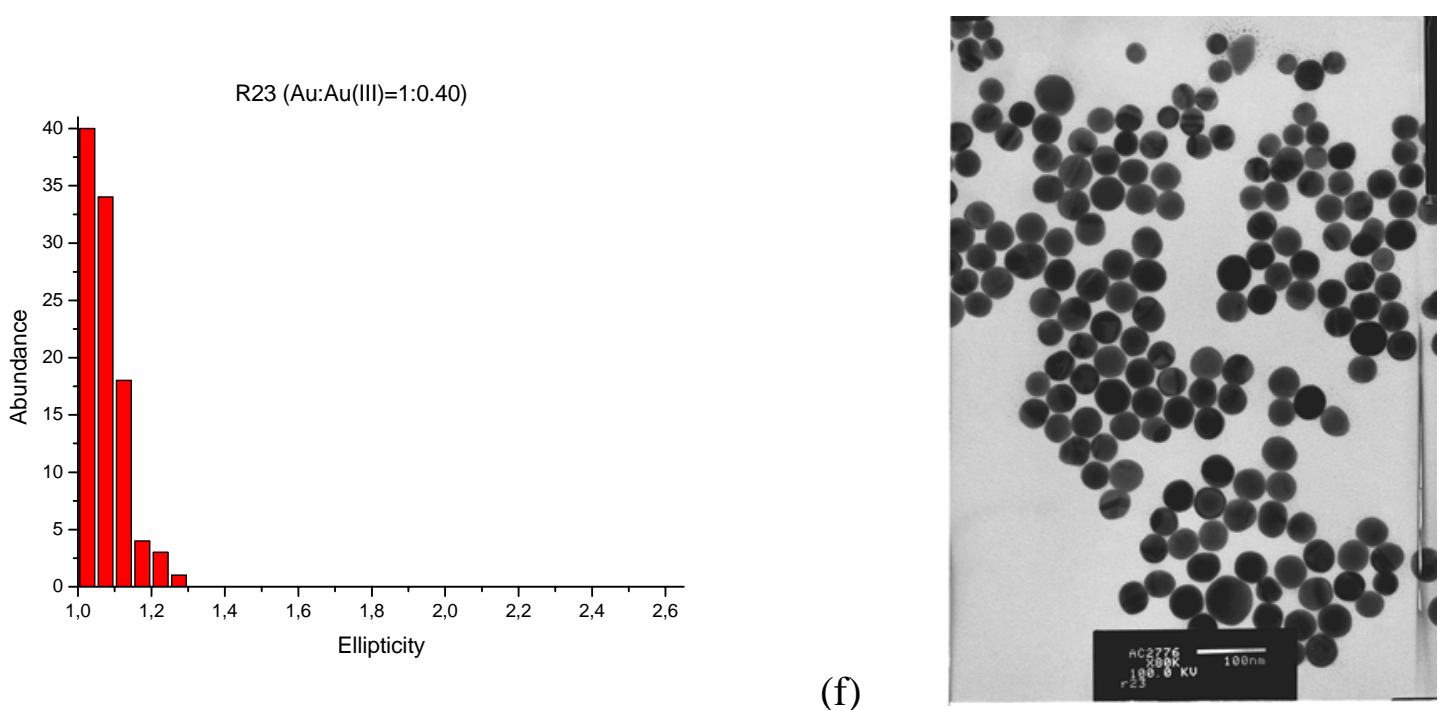

(f) 
Supporting Information Figure 2. Length and width distributions (histograms) of $\mathrm{Au}$ nanoparticles before (a) and after addition of $\mathrm{HAuCl}_{4}$ with different $\mathrm{Au}: \mathrm{Au}^{\mathrm{III}}$ molar ratios [1:0.125 (b), 1:0.25 (c), 1:0.30 (d), 1:0.34 (e), 1:0.4 (f)] in the presence of CTAB $0.05 \mathrm{M}$.
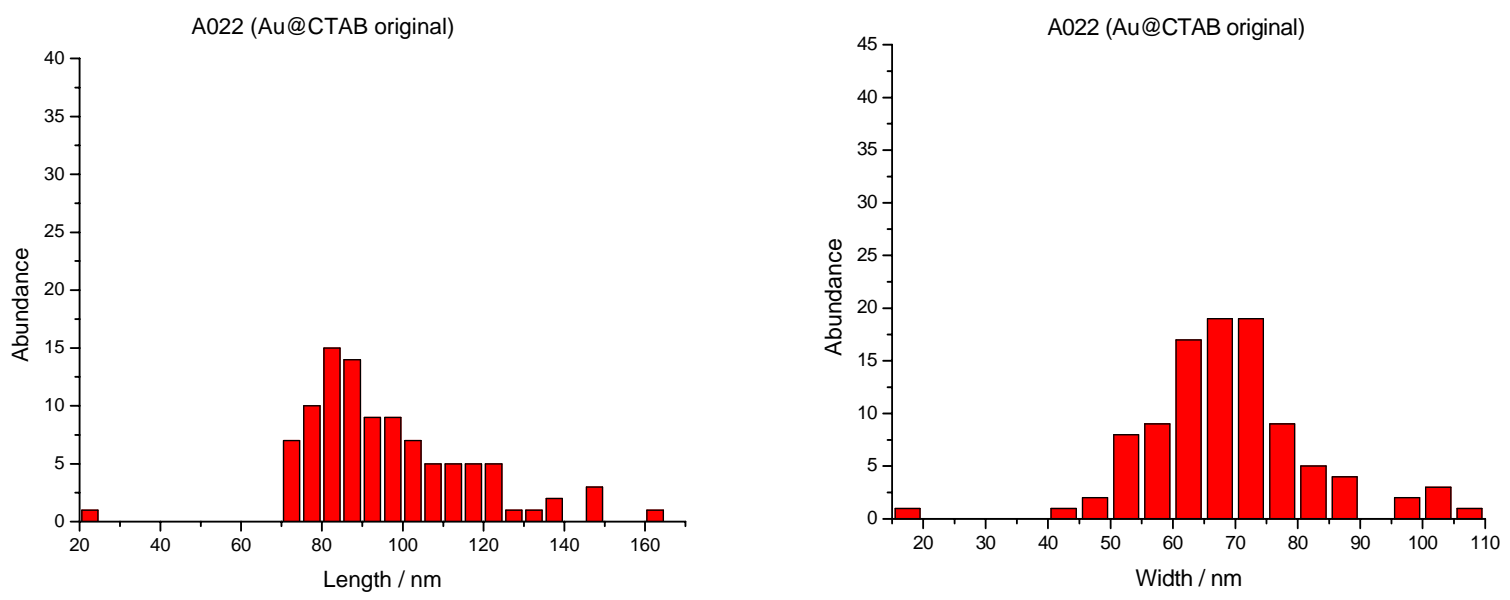

(a)
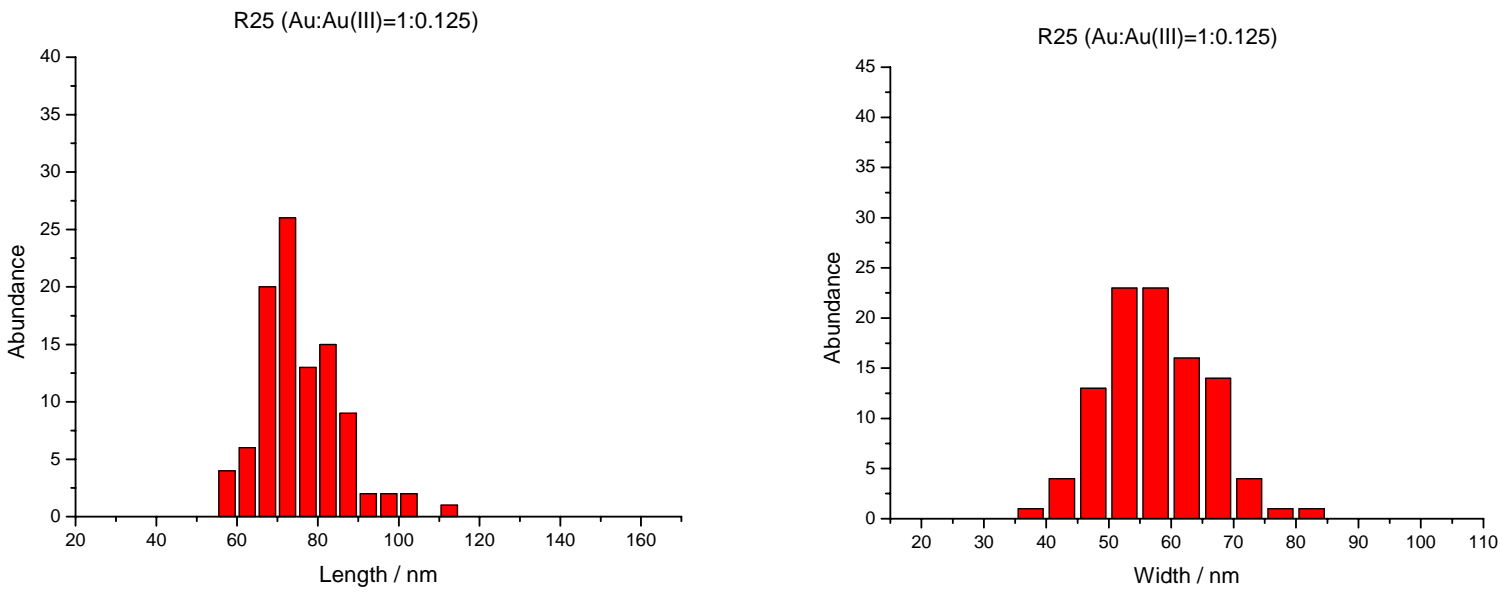

(b)
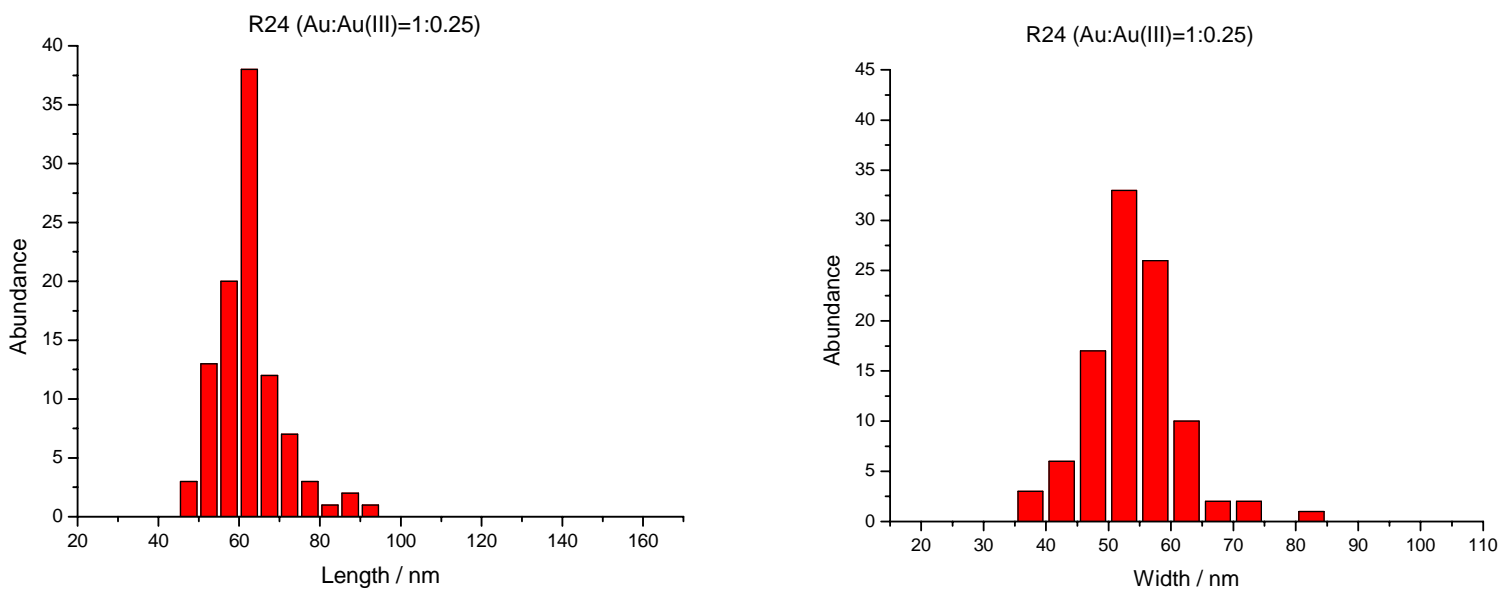

(c) 

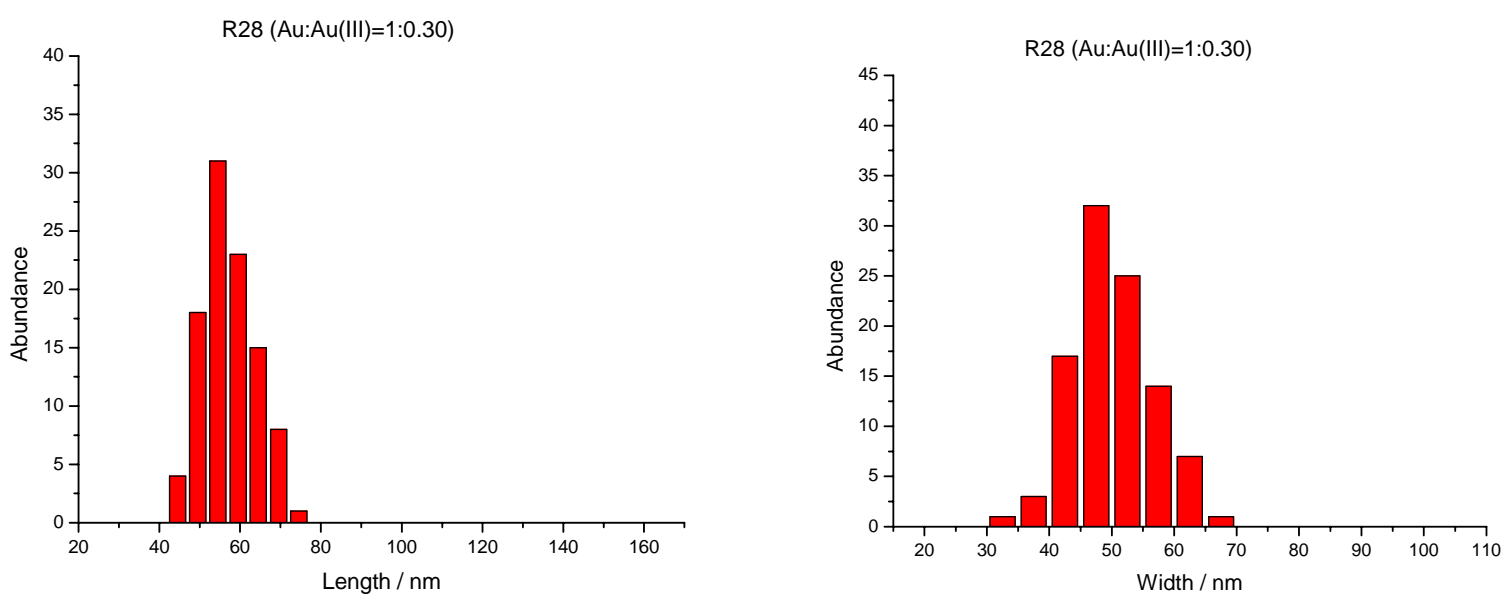

(d)
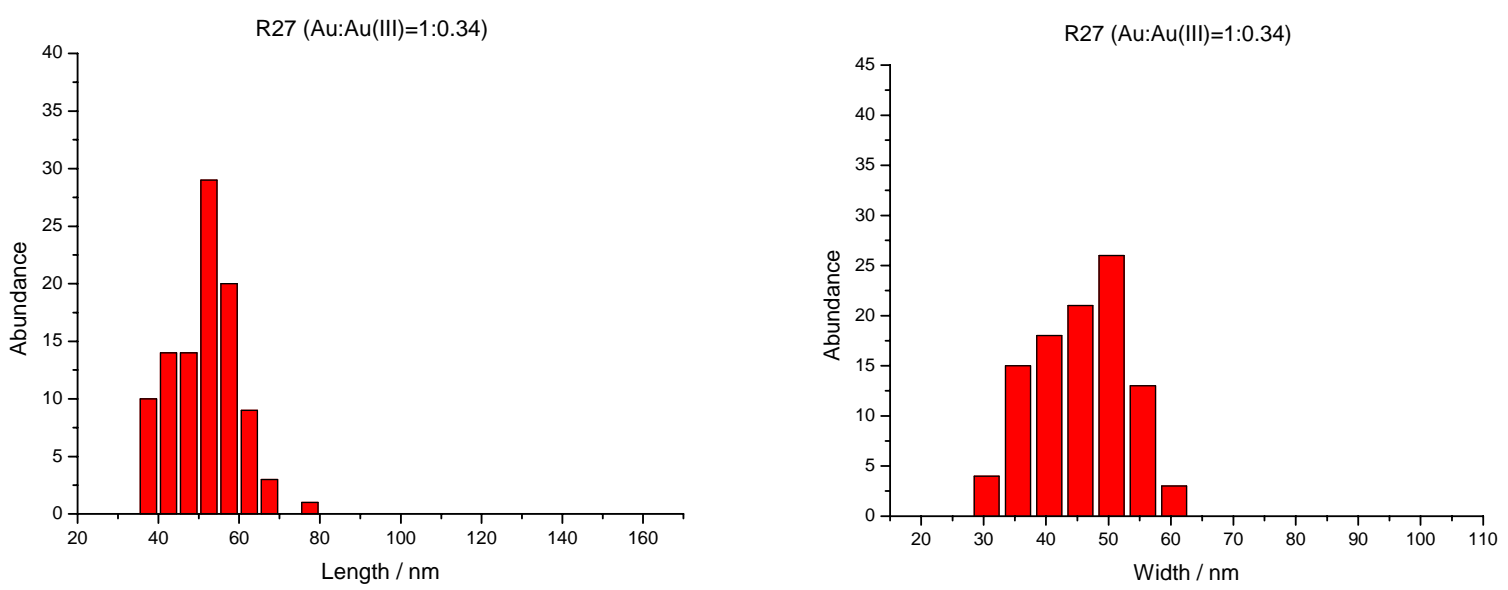

(e)
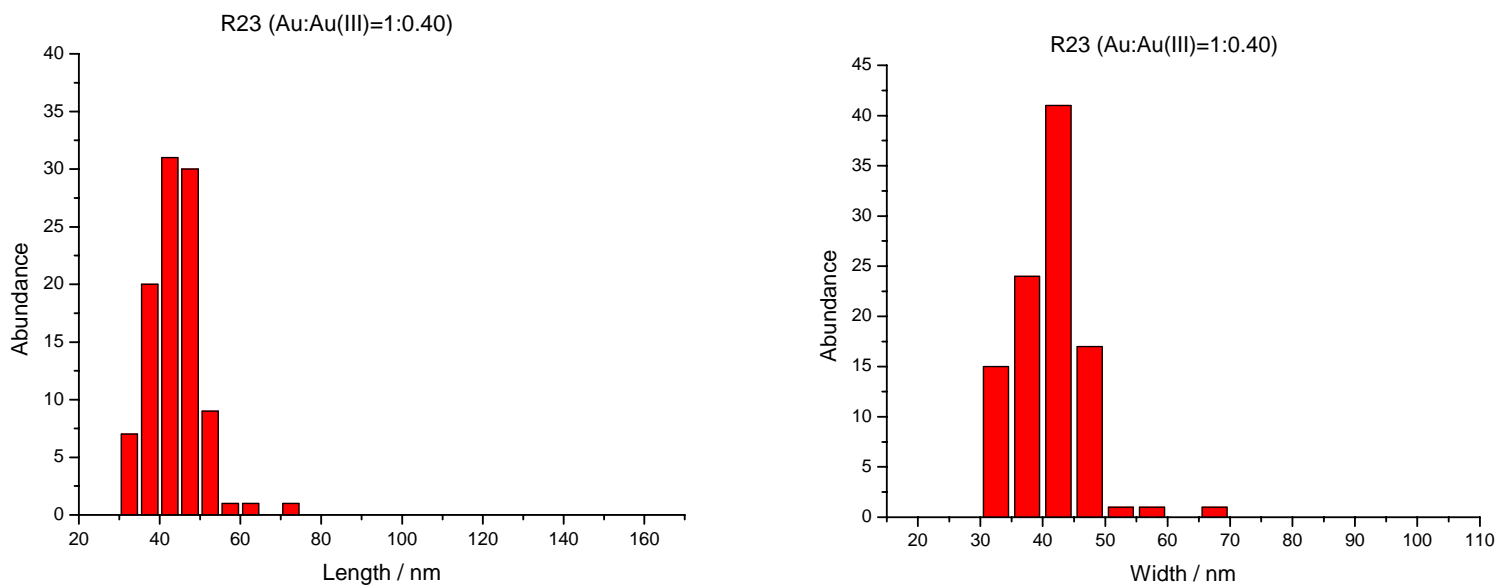

(f) 